\title{
Tuberculin Unit
}

National Cancer Institute

\section{Source}

National Cancer Institute. Tuberculin Unit. NCI Thesaurus. Code C65132.

An arbitrary unit of tuberculin dosage defined by comparison of clinical response to a preparation of the purified protein derivative standardized for use in humans for tuberculin skin test reaction. 